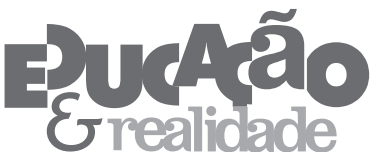

\section{Apresentação Educação Especial e Processos de Escolarização}

Carla K. Vasques'

Claudio Roberto Baptista'

'Universidade Federal do Rio Grande do Sul (UFRGS), Porto Alegre/RS-Brasil

O debate contemporâneo sobre educação especial permite que esta seja identificada como uma área de conhecimento em percurso acelerado de mudança. Os processos de escolarização das pessoas consideradas público alvo da educação especial constituem o cerne dessa mudança, no sentido de alteração de rotas, redimensionamento de proposições, implementação de políticas, mas, sobretudo, reinvenção dos modos de se compreender quem são e como se constituem esses sujeitos. Partimos, portanto, da afirmação de algumas premissas que, ao valorizem a experiência escolar, anunciam a necessidade de que essas mudanças estejam fortemente ancoradas nos conhecimentos relativos a um sujeito que se constitui historicamente, por meio das relações que são produto e produtoras da interação de cada integrante das teias vivas e dinâmicas que assumem a configuração de instituições - escola, família, grupos sociais, espaços de trabalho, dentre outras.

A centralidade dos processos de escolarização, como um dos eixos da orientação temática do presente dossiê, é facilmente justificada quando consideramos a história da educação brasileira. Na educação especial, a escolarização não é apenas uma proposição recente e tardia, mas se anuncia como território de controvérsias ao evocar polarizações que nem sempre consideram que a trajetória escolar, na escolar regular, seria uma meta defensável. Em direção que problematiza tais questionamentos, o conjunto de textos aqui apresentados tende a nos auxiliar na compreensão de que a pesquisa acadêmica deve ser valorizada como campo de conhecimento e debate, em função de seu compromisso com o novo, que se materializa na identificação do investimento naquilo que ainda não sabemos. O saber sobre a vida das pessoas com deficiência ou síndromes ${ }^{1}$ nos mostra o recorrente predomínio de fenômenos vinculados à exclusão social que têm sido fortemente justificados pela suposta incompletude que se associa ao mito da imutabilidade, de precárias respostas à intervenção contextual e educativa. Tais crenças, há muito questionadas, continuam presentes vivamente no meio social e acadê-

Educação \& Realidade, Porto Alegre, v. 39, n. 3, p. 659-664, jul./set. 2014.

Disponível em: <http://www.ufrgs.br/edu_realidade> 
mico, exigindo que as reflexões que as colocam em suspensão tenham lastro para fazer frente à tendência valorizadora do já sabido e das conveniências institucionais que têm feito da pessoa com deficiência um alvo de interesses muito variados: afirmação de políticas vinculadas ao assistencialismo e à dependência; compreensão de que, para tais sujeitos, a responsabilidade estatal seria relativizada quando se pensa as políticas sociais; valorização de um conhecimento técnico que tende a esvaziar o investimento social e pedagógico; manutenção de precariedades no que se refere à existência de serviços e de investimento na formação de profissionais com conhecimento para assegurar a escolarização como um processo que também caracteriza a vida desses alunos.

Se essa é a tendência histórica, o olhar dirigido ao futuro deveria ser capaz de colher os pontos de dissonância de um presente nada homogêneo. Deveria nos auxiliar a operar diferenciações, no sentido das ideias de Gregory Bateson (1989) que destaca o pensar em termos de histórias como característica eminentemente humana. Histórias que congregam a singularidade na multiplicidade e que, a partir desse destaque à dimensão singular, nos auxiliam a compreender a política como campo de ressignificação, afastando-se de acepções que a identificam como instância de resolução de problemas sociais e nos auxiliando a colher sua potência como campo de ressignificação de pensamentos, nomeações e de práticas. Essa compreensão está em sintonia com a perspectiva da análise cognitiva das políticas, em linha com as proposições de autores como Muller e Surel (2002). Temos assim um contexto de produção de ideias que torna possível pensarmos em alternativas de visibilidade das reflexões. Nossa referência passa a ser a escrita acadêmica, a necessidade de colocar em evidência ideias que se vinculam à pesquisa, que permitem a identificação do novo, que mostram pontos de confluência ao compartilharem premissas. Essa tendência a compartilhar se situa no plano das premissas, pois ao observarmos outras dimensões desse conjunto de textos percebemos que a pluralidade passa a ser referência: são diferentes os campos teóricos implicados, assim como são distintas as temáticas que se abrem em um leque de possibilidades analíticas. A pluralidade também é marca predominante quando consideramos os territórios - geográficos ou institucionais - de proveniência dos autores envolvidos.

O presente dossiê reúne diferentes contribuições que compartilham essa aposta de uma história viva a ser conhecida, inventada, tecida. Os pontos de referência são múltiplos e reúnem o investimento no debate acerca de sujeitos que se constituíram historicamente como alvo de técnicas especializadas - os sujeitos com autismo ou transtornos globais do desenvolvimento.

Carla K. Vasques e Claudio Roberto Baptista, no texto Transtornos Globais do Desenvolvimento e Escolarização: o conhecimento em perspectiva, apresentam reflexões que têm como foco a escolarização 
de sujeitos com transtornos globais do desenvolvimento no âmbito da produção discente brasileira. A proposta de análise de um conjunto de produções teve como meta a instituição de um diálogo com a hermenêutica filosófica para tornar viáveis questões atinentes ao modo de leitura dos textos, das perguntas, dos sujeitos. Tomando como referência um conjunto de produções vinculadas à pesquisa desenvolvida na pósgraduação stricto sensu, os autores fizeram emergir interrogações sobre as áreas implicadas, as temáticas emergentes, assim como ao lugar conferido à escola e à escolarização.

Colocando em debate o quanto as supostas restrições dirigidas à escolarização desses sujeitos são uma produção da história, Catia Giaconi e Maria Beatriz Rodrigues, no texto Organização do Espaço e do Tempo na Inclusão de Sujeitos com Autismo, propõem uma análise que tem como meta as reflexões acerca da escolarização de sujeitos que apresentam essa síndrome realizada na escola comum, na Itália. Essas autoras discutem os pressupostos históricos e normativos da inclusão escolar e laboral, ou seja, investem na apresentação daquilo que designam de o estado da arte da inclusão de sujeitos com autismo, nos contextos italiano e internacional. A partir desse debate, buscam abordar a ação pedagógica e os indícios de práticas docentes que tendem a assegurar a escolarização desses sujeitos. Uma dimensão inovadora presente nessas reflexões é aquela que aborda uma tipologia de sujeito em um contexto que produziu uma alteração radical na política de educação naquele país.

O texto Pessoas com Deficiência e Escola: principais mudanças na experiência italiana, de autoria de Giovanna Di Pasquale e Marina Maselli, permite a ampliação da análise sobre o contexto italiano, considerando as alterações político-pedagógicas no que se refere à educação especial e à inclusão escolar. Essas autoras abordam o plano normativo, apresentam um resgate histórico acerca da temática e identificam pontos de tensão que continuam sendo merecedores de investimento do trabalho pedagógico e político: colaboração entre os diferentes profissionais envolvidos; interação entre a família e a escola; atenção ao plano curricular no sentido de aproximar as necessidades singulares do aluno e o planejamento coletivo dirigido ao grupo-classe; relação escola e ambiente social para que a experiência de formação tenha continuidade e múltiplas referências.

O Brasil tem em sua história dos últimos 10 anos, como é explicitado em vários dos textos que compõem o presente dossiê, muitas evidências - políticas e acadêmicas - de valorização dos processos inclusivos das pessoas com deficiência. Os estudos relativos à educação especial destacam iniciativas de implementação de políticas, com predomínio de potencial inovador que se faz presente em redes municipais de ensino. Essas diretrizes são identificadas no texto de Rosângela Gavioli Prieto, Karina Soledad Maldonado Molina Pagnez e Roseli Kubo Gonzalez, Educação Especial e Inclusão Escolar: tramas de uma política 
em implantação. Essas autoras analisam a política de educação especial em curso no município de São Paulo, focalizando alguns dos projetos que integram um programa criado em 2010. De acordo com a autora, é possível identificar movimentos existentes no município para instituir ações que dão apoio à permanência dos alunos com deficiência nas classes comuns, pela via da ampliação das ações de suporte pedagógico, de formação específica e continuada, assim como do aumento do número de serviços e de agentes de inclusão escolar junto às escolas municipais.

O universo dos sistemas municipais de ensino também á alvo de atenção no texto Atos de Ler a Educação Especial na Educação Infantil: reordenações políticas e os serviços educacionais especializados, de autoria de Fabiane Romano de Souza Bridi e Melina Chassot Benincasa Meirelles. Esse artigo tem como meta produzir uma leitura da educação especial na educação infantil no contexto da Rede Municipal de Ensino de Santa Maria/RS. Foram utilizadas informações do Censo da Educação Básica, incluindo as informações vinculadas aos microdados do censo escolar do INEP. Na análise são abordadas questões contemporâneas como: a necessidade de ampliação das matrículas dos alunos da Educação Especial na Educação Infantil e a oferta dos serviços especializados dirigidos a essas crianças; as singularidades dos processos de identificação; as variabilidades compreensivas acerca de como se constituem os serviços de atendimento educacional na primeira infância. Trata-se de temas que anunciam também a grande exigência de formação qualificada. Essa necessidade mostra-se como um aspecto unificador entre a educação especial e a educação infantil.

A formação dos agentes desse processo é uma dimensão evocada permanentemente, na pesquisa acadêmica, como estrutural. O desafio associado às singularidades de alguns sujeitos soma-se à busca de problematizar a ação pedagógica dirigida a todos os alunos. Esse é o campo temático abordado por Denise Meyrelles de Jesus, Alexandro Braga Vieira e Ariadna Pereira Siqueira Effgen no texto Pesquisa-Ação Colaborativo-Crítica: em busca de uma epistemologia. Tais autores partem do desafio associado à formação para instituir uma análise teórico-metodológica que toma o fazer e o pesquisar como eixos necessariamente complementares. Essa compreensão nos remete à circularidade de um processo como aquele educativo: busca de pistas que permitem conhecer algo que muda continuamente e que só pode ser operada se compreendida como ato, ação, partilha. Evocando teóricos como Barbier, Morin e Souza Santos, o texto problematiza a natureza do conhecimento e discute os resultados produzidos por essa metodologia de investigação, com ênfase em conceitos como: pesquisador coletivo, processo de implicação e pesquisa-ação. No caso desse artigo, o contexto de emergência dessas ideias é o estado do Espírito Santo e as pesquisas que buscam conhecer as singularidades e os pontos de avanço potencial para a implementação de políticas de inclusão escolar. 
Outros espaços geográficos da cena educacional brasileira são evocados em textos que integram o presente dossiê. No texto Indicadores Educacionais sobre a Educação Especial no Brasil e no Paraná, de autoria de Silvia Márcia Ferreira Meletti, foi apresentada uma análise acerca da escolarização de alunos público alvo da educação especial por meio dos dados oficiais do poder público sobre o acesso e permanência desta população na Educação Básica. No texto, são utilizados microdados do Censo da Educação Básica brasileira e do Paraná, estado que se constitui como um território singular quando discutimos a inclusão escolar em função de sua tendência de implementação de políticas que nem sempre estiveram em sintonia com as diretrizes nacionais. As análises apontam, a despeito da implantação da política de educação inclusiva, que: formas de atendimento segregado ainda estão marcadamente presentes no Paraná; a concentração de matrículas ocorre nas primeiras séries do ensino fundamental, com ampla defasagem idade/série e o baixo número de matrículas no atendimento educacional especializado.

As singularidades que integram as diferentes análises mostram múltiplos desafios que se vinculam à necessária redefinição da escola diante da meta de escolarização das pessoas com deficiência. A atenção às trajetórias dos sujeitos não deveria se restringir ao âmbito estritamente escolar, pois a vida do jovem e do adulto apresenta progressivamente novos desafios.

Os estudos da área evidenciam percursos escolares que tendem a se encerrar nos primeiros anos do ensino fundamental. Nesse sentido, as interrogações que marcam os possíveis aspectos que justificam uma trajetória escolar com indicadores de avanço para os níveis mais elevados merece toda atenção e disponibilidade compreensiva. Rosimeire Maria Orlando e Katia Regina Moreno Caiado, no texto Professores Universitários com Deficiência: trajetória escolar e conquista profissional, analisam a educação escolar de pessoas com deficiência. Partindo do pensamento de Bourdieu, o texto aborda a trajetória escolar de professores universitários, com o objetivo de compreender influências sobre desempenho escolar e identificar razões da distinção que os tornou minoria dentre os milhares de outras pessoas com deficiência que não atingem um elevado patamar de educação formal. O estudo indica que a valorização familiar pelo estudo, a ação da instituição escolar e a distribuição do capital cultural objetivado são indicativos do desempenho escolar e profissional dos sujeitos investigados.

O universo do trabalho foi também objeto de atenção de Liliana Maria Passerino e Ana Cristina Cypriano Pereira no texto Educação Inclusão e Trabalho: um debate necessário. Essas autoras se ocupam da associação entre o conceito de inclusão, em suas diferentes acepções, e aquele associa à profissionalização, à inserção da pessoa com deficiência no mundo do trabalho. A análise dos avanços evidenciados em território nacional e dos obstáculos frequentes toma a pesquisa que parte 
das trajetórias de sujeitos específicos para avançar em terreno propositivo que investe em soluções assistidas e ferramentas digitais.

O panorama instituído pelas reflexões que integram o presente dossiê colocou em destaque vários dos nós que tem caracterizado o desafio associado à escolarização de pessoas com deficiência: a pluralidade de sentidos presentes na identificação do sujeito alvo da educação especial; a variabilidade entre os contextos escolares; as oscilações relativas às ênfases associadas à inclusão escolar quando consideramos o território brasileiro e experiências internacionais; a busca dos pontos de conexão entre o plano normativo e a vida das escolas e tantos outros. Nossa expectativa é o elenco de textos que ora se apresenta seja lido como um encontro promissor, provocador de novas interrogações.

\section{Nota}

1 O sujeito da educação especial tem sido identificado, no Brasil, como a pessoa com deficiência, com transtornos globais de desenvolvimento ou com altas habilidades/superdotação. Essa definição tem como referência a Política Nacional de Educação Especial na perspectiva da Educação Inclusiva (Brasil, 2008).

\section{Referências}

BATESON, Gregory. Mente e Natureza. Rio de Janeiro: Francisco Alves, 1986.

BRASIL. Ministério da Educação. Secretaria de Educação Especial. Política Nacional de Educação Especial na Perspectiva da Educação Inclusiva. Brasília: MEC/SEESP, 2008.

MULLER, Pierre; SUREL, Yves. A Análise das Políticas Públicas. Pelotas: EDUCAT, 2002.

Carla K. Vasques é psicóloga, com formação em psicanálise. Doutora em Educação/UFRGS. Professora da Faculdade de Educação e do Programa de Pós-Graduação em Educação da UFRGS. Coordenadora do Núcleo de Pesquisa em Psicanálise, Educação e Cultura, NUPPEC/UFRGS. Desenvolve pesquisas sobre sujeitos da educação especial e processos de escolarização. E-mail: k.recuero@gmail.com

Claudio Roberto Baptista é doutor em Educação pela Università di Bologna. Professor da Faculdade de Educação e do Programa de Pós-Graduação em Educação da UFRGS. Coordena o NEPIE- Núcleo de Estudos em Políticas de Inclusão Escolar da UFRGS. Desenvolve pesquisas sobre os processos de inclusão escolar e sobre a educação especial.

E-mail: baptistacaronti@yahoo.com.br 